\title{
Sperm storage and low incidence of multiple paternity in the European pond turtle, Emys orbicularis: A secure but costly strategy?
}

\author{
S. Roques*, C. Díaz-Paniagua, A. Portheault, N. Pérez-Santigosa, J. Hidalgo-Vila \\ Estacion Biológica de Doñana (CSIC), Auda de Maria Luisa s/n, Pabellón del Perú, 41013 Sevilla, Spain
}

Keywords:

Emys orbicularis

Sperm storage

Multiple paternity

Microsatellite

Conservation

\begin{abstract}
A B S T R A C T
The freshwater pond turtle, Emys orbicularis, has recently suffered from population declines throughout its range, mainly due to habitat destruction. The mating strategies of this species were studied using genetic data from successive clutches within and between years. To test for the occurrence and frequency of multiple paternity and sperm storage, genetic paternity at six microsatellite markers was assessed in 114 embryos and hatchlings from single and subsequent clutches of 11 females (including clutches from the same or consecutive years). Multiple paternity was rare and only found in two out of 20 clutches from 11 females. All annual successive clutches and $58 \%$ of the clutches in the next year, were fertilized with sperm from the same male. The use of stored sperm is thus a frequent strategy in E. orbicularis. However, hatching rate, hatchling mass, and hatchling length decreased in clutches fertilized by stored sperm, suggesting sperm depletion or deterioration through time. The occurrence of stored sperm despite an associated reduced reproductive output indicated that mating and/or the fertilization process is costly to females. The low incidence of multiple paternity may simply be the residual consequence of the capacity to store viable sperm. These results provide important and innovative insights for the conservation of E. orbicularis. In threatened populations, management strategies may aim to enhance effective copulations in order to increase the reproductive output of females.
\end{abstract}

\section{Introduction}

Multiple paternity and sperm storage strategies have been investigated in many reptile taxa to understand mating strategies and to test hypotheses regarding mating behaviour and reproductive systems (Olsson and Shine, 1997; Gist et al., 2001; Pearse and Avise, 2001; Crim et al., 2002; Hoekert et al., 2002; Pearse et al., 2002; Tenessen and Zamudio, 2003; Lee and Hays, 2004). In turtles, the capacity of females to utilize stored sperm was first deduced from the asynchrony of copulation and egg maturation (Devine, 1984), from experiments in captivity in which females were isolated from males (Goin et al., 1978; Palmer et al., 1998), and from observations of storage organs (Gist and Jones, 1989; Gist and Congdon, 1998). However, such observations do not identify offspring from different males, so that the quantitative and qualitative contributions of stored sperm to successive clutches could not be evaluated. Identification of paternal alleles in successive clutches has confirmed both multiple paternity and sperm storage over both short and long periods in turtles (Pearse and Avise, 2001; Pearse et al., 2001; Crim et al., 2002; Moore and Ball, 2002; Roques et al., 2004). For species that lay multiple

\footnotetext{
* Corresponding author: Tel.: +34 954232340; fax: +34 954621125.
}

E-mail address: severine@ebd.csic.es (S. Roques). 
clutches per season, the time for effective matings is the interval between oviposition and the subsequent ovulation (Gist and Congdon, 1998). Given the short length of this interval, sperm storage was considered to be a strategy that enabled females to fertilize consecutive clutches in a single reproductive season, without the necessity of additional matings (Fitzsimmons, 1998; Kichler et al., 1999; Roques et al., 2004).

On the other hand, the frequency and the benefits of long term sperm storage (across years) are not well known in turtles (Palmer et al., 1998; Pearse et al., 2001). It remains unclear why fertilization of successive clutches with the sperm from the same single or multiple matings could be advantageous. Pearse et al. (2001) found that $23 \%$ of painted turtles (Chrysemys picta) used sperm that had been stored as long as three years to fertilize the whole or part of their clutches, despite re-mating each breeding season. They suggested that females probably re-mate for reasons other than the acquisition of gametes for fertilization, such as to increase genetic diversity of offspring. The effect of stored sperm on fertility and/or hatching success of across-year clutches is contradictory, with no significant change in some species (Pearse et al., 2001, 2002), but a decrease in others, suggesting sperm depletion (Gist and Jones, 1989). In other reptiles, sperm storage may involve male sperm competition, or also, females may be able to control paternity of their offspring by a selective use of sperm (Olsson et al., 1997). Moreover, through sperm storage, female turtles may receive the possible benefits of multiple paternity over a long term period. A recent assessment of hatchling success in multiple sired clutches, however, failed to find any correlation between multiple paternity and clutch fitness, suggesting that main benefits of multiple paternity are probably indirect, such as the increase of genetic variation among offspring (Pearse et al., 2001; Lee and Hays, 2004). Finally, stored sperm may simply serve as a "reserve" in case of low availability of males.

The range of the freshwater pond turtle, Emys orbicularis extends from north Africa to eastern Europe and central Asia, as far as the Aral sea (Iverson, 1992; Fritz, 2001). This species is threatened throughout its range and has suffered population declines, mainly due to habitat disturbance (degradation and fragmentation). In southern areas, the species has a long annual reproductive period and females may be courted by more than one male within a season (Rovero et al., 1999). Courtship has been observed as early as autumn, but the main mating period occurs in spring, from March to June. Copulations always occur underwater (Rovero et al., 1999). In our study area, females lay 1-2 clutches within a year (clutch size: 3-10) about 30 days apart, between May and July (this study).

Genetic data from successive clutches within and between years can provide important insights into the reproductive behaviour and mating strategies of freshwater turtles. In this study, we use six microsatellite markers to test for the occurrence and frequency of multiple paternity and sperm storage in successive clutches of the European pond turtle, E. orbicularis, over two breeding seasons in south-western Spain. Hatching success of different clutches fertilized by the same male was compared, in order to determine if the quality of stored sperm decreases through subsequent reproductive seasons (i.e. sperm depletion or degradation).

\section{Materials and methods}

\subsection{Sampling}

During June and July of 2002 and 2003, turtles were trapped in two ponds ("Laguna Dulce", Pond 1, $60000 \mathrm{~m}^{2}$ and "Los Hermanillos", Pond 2, $2900 \mathrm{~m}^{2}$ ) inside Doñana National Park (SW Spain). Ponds were separated by about $3 \mathrm{~km}$. We captured 34 males and 35 females in Pond 1 and 11 males and 12 females in Pond 2. Turtles were individually marked by notching the shell. We selected 11 gravid females in 2002 that were induced to lay their eggs by injection of $0.1-$ $0.3 \mathrm{ml}$ of oxytocin (Ewert and Legler, 1978). Eggs were transferred to the laboratory, where they were weighed, measured, and incubated in moistened vermiculite at constant temperature $\left(27^{\circ} \mathrm{C}\right)$ until hatching. The females were released into their respective pond immediately after oviposition. We frequently recaptured individuals over the course of this study, and obtained multiple clutches from six females and single clutches from the remaining five (Table 1). Blood samples from the 11 gravid females and of 24 additional males and females were obtained to genotype mothers and candidate fathers, and to calculate allelic frequencies in the adult population.

\subsection{Microsatellite analysis}

Blood samples obtained from adults and the tip of the tail from live hatchlings (a few days old) were preserved in $100 \%$ ethanol. Genomic DNA was extracted using lithium chloride method (Gemmell and Akiyama, 1996). For unhatched eggs, DNA was extracted from embryonic tissue, using phenolchloroform (Sambrook et al., 1989). Genotypes were determined at six microsatellite loci, CmuD51, CmuD62, CmuD93, CmuD114, CmuD88, CmuD87, specifically designed for the bog turtle, Glyptemys muhlenbergii (King and Julian, 2004). PCRs were performed in $20 \mu \mathrm{l}$ reaction volume $\left(2 \mathrm{mM} \mathrm{MgCl}_{2}, 0.2 \mu \mathrm{M}\right.$ of each primer, $1 \times$ Taq Buffer, 0.5 units of Taq polymerase, $0.25 \mathrm{mM}$ of each dNTP and 20-50 ng of DNA template). The second primer of each pair was end labelled with one of the three fluorescent labels: yellow (HEX) for CmuD62, CmuD93, green (TET) for CmuD114, CmuD87 and blue (FAM) for CmuD88, CmuD51. PCR cycling conditions for CmuD114 and CmuD88 were as follows: a denaturing step of $2 \mathrm{~min}$ at $94^{\circ} \mathrm{C}, 35$ cycles of $30 \mathrm{~s}$ at $92^{\circ} \mathrm{C}, 30 \mathrm{~s}$ at $58^{\circ} \mathrm{C}, 30 \mathrm{~s}$ at $72{ }^{\circ} \mathrm{C}$ and a final step of $5 \mathrm{~min}$ at $72^{\circ} \mathrm{C}$. For the remaining loci, cycling steps were: a denaturing step of $2 \mathrm{~min}$ at $94^{\circ} \mathrm{C}, 10$ cycles of $30 \mathrm{~s}$ at $92^{\circ} \mathrm{C}, 30 \mathrm{~s}$ at $60^{\circ} \mathrm{C}$ with a $1^{\circ} \mathrm{C}$ decrease at each cycle, $30 \mathrm{~s}$ at $72{ }^{\circ} \mathrm{C}, 24$ cycles of $30 \mathrm{~s}$ at $92^{\circ} \mathrm{C}, 30 \mathrm{~s}$ at $50^{\circ} \mathrm{C}, 30 \mathrm{~s}$ at $72{ }^{\circ} \mathrm{C}$ and a final step of $5 \mathrm{~min}$ at $72^{\circ} \mathrm{C}$. PCR products were analysed on an automatic ABI prism sequencer (ABI 310). For each sample, $1-4 \mu \mathrm{l}$ of PCR product was diluted in $90 \mu \mathrm{l}$ of water. Two microlitres of dilution was mixed with $12 \mu \mathrm{l}$ of formamide plus $0.5 \mu \mathrm{l}$ of internal size standard (red colour TAMRA $350 \mathrm{bps}$ ) and denatured $3 \mathrm{~min}$ at $95^{\circ} \mathrm{C}$. Data collection and analysis, as well as automated scoring of the alleles for each sample, were performed using GeneScan 3.1.2 Analysis software (Perkin-Elmer). Tabulation of data for each locus was conducted with the ABI PRISM Genotyper 2.5 software (Perkin-Elmer). 
Table 1 - Emys orbicularis - clutch data for each female (sampling year, clutch name and size, number of offspring genotyped), inferred paternal alleles from six

microsatellite loci, occurence of multiple paternity (MP) in two ponds (1 and 2) in south-western Spain

\begin{tabular}{|c|c|c|c|c|c|c|c|c|c|c|c|c|}
\hline \multirow[t]{2}{*}{ Female } & \multicolumn{5}{|c|}{ Clutch data } & \multicolumn{6}{|c|}{ Inferred paternal alleles } & \multirow[t]{2}{*}{ Males } \\
\hline & Year & Name & Size & Gtp & MP & CmuD51 & CmuD62 & CmuD93 & CmuD114 & CmuD88 & CmuD87 & \\
\hline \multicolumn{13}{|l|}{ Pond 1} \\
\hline 1689 & 2003 & I & 6 & 5 & & 267,271 & 188 & 227,231 & 120, 132 & 145 and/or149 & 233 or 229,245 & D1 \\
\hline \multirow[t]{3}{*}{879} & 2002 & $\mathrm{~F}$ & 6 & 6 & & 267, 271 & 188 and/or 192 & 227, 231 & 128,132 & 145,149 & 233 or 229,245 & D1 \\
\hline & & AJ & 7 & 7 & & 267 (or 287), 271 & 188,192 & 227,231 & 128,132 & 145,149 & 233 or 229,245 & D1 \\
\hline & 2003 & E & 6 & 6 & & 255,283 & 188,200 & 239,255 & 124,128 & 141, 159 & 229,233 & D2 \\
\hline \multirow[t]{2}{*}{999} & 2002 & $\mathrm{Ai}$ & 5 & 5 & & 255,283 & 188,200 & 255 & 124,128 & 141, 159 & 233,249 & D2 \\
\hline & 2003 & $\mathrm{M}$ & 6 & 4 & & 255 (or 271 ), 283 & 172 and/or 188 & 239,255 & 124,128 & 141, 159 & 233,249 & D2 \\
\hline \multirow[t]{3}{*}{1175} & 2002 & $\mathrm{z}$ & 7 & 3 & & 271,275 & 184 and/or 188 & 227,235 & 132 & 175 & 229,233 or 237 & D3 \\
\hline & & $\mathrm{AL}$ & 8 & 7 & & 271,275 & 184 and/or 188 & 227,235 & 112,132 & 149,175 & 233 and/or 237 & D3 \\
\hline & 2003 & $\mathrm{~L}$ & 7 & 3 & & 271,275 & 184 and/or 188 & 227,235 & 112,132 & 149,175 & 233 and/or 237 & D3 \\
\hline \multirow[t]{2}{*}{1519} & 2002 & $\mathrm{AK}$ & 5 & 5 & & 263,267 & 180, 192 & 239, 251 & 128 and/or 132 & 149, 171 & 233,245 & D4 \\
\hline & 2003 & $\mathrm{~N}$ & 7 & 6 & & 263,267 & 180, 192 & 239, 251 & 128 and/or 132 & 149, (163 or)171 & 233,245 & D4 \\
\hline 1159 & 2002 & $\mathrm{H}$ & 8 & 8 & & 263,283 & 196,184 or 188 & 243,251 & 132 & 145,155 & 233, 241 & D5 \\
\hline 1241 & 2002 & $\mathrm{AM}$ & 8 & 7 & & $255,279,283$ & 188 & 227,239 & 120,124 & 159 & 237 & D6 \\
\hline \multicolumn{13}{|l|}{ Pond 2} \\
\hline 1305 & 2003 & C & 10 & 6 & & 255,275 & 184, 192 & 227,231 & 120,136 & 163,171 & 233,241 & $\mathrm{H} 1$ \\
\hline \multirow[t]{3}{*}{1599} & 2002 & A & 10 & 8 & & 255,275 & 184, 192 & 227, 231 & 120,136 & 163,171 & 241 & $\mathrm{H} 1$ \\
\hline & & AG & 3 & 3 & & 255,275 & 184, 192 & 227,231 & 120,136 & 163,171 & 241 & H1 \\
\hline & 2003 & $\mathrm{H}$ & 6 & 6 & & 271,275 & 180, 184, 192 & 235 & 132,144 & 137, 171 & 225,245 & $\mathrm{H} 2$ \\
\hline \multirow[t]{2}{*}{1564} & 2002 & C & 7 & 4 & & 271,275 & 184, 192 & 235 & 132,144 & 137,171 (or 167 ) & 225,245 & $\mathrm{H} 2$ \\
\hline & 2003 & B & 9 & 9 & $\mathrm{X}$ & $271,243,283$ & 184,188 & 235 (or 255), 231, 251 & 132 & $137,145,179$ & $225,245,241$ & $\mathrm{H} 2+\mathrm{H} 3$ \\
\hline 1556 & 2002 & $\mathrm{AH}$ & 6 & 6 & $\mathrm{X}$ & $271,259,287$ & 184,192, 188 & $235,227,231$ & 132,128 & $137,171,155$ & $225,245,237$ & $\mathrm{H} 2+\mathrm{H} 4$ \\
\hline
\end{tabular}




\subsection{Statistical analysis}

Allelic frequencies, heterozygosities (both observed and expected) were calculated using the program GENETIX for 35 individuals ( $n=26$ from Pond 1 and $n=9$ from Pond 2). Locus conformance to Hardy-Weinberg equilibrium and heterozygote deficiency was assessed with exact tests implemented in GENEPOP 3.1 (Raymond and Rousset, 1995) using specified Markov chain parameters of 5000 dememorization steps followed by 500 batches of 2000 iterations per batch. Significance levels for multiple comparisons of loci across samples were adjusted using a sequential Bonferroni correction (Rice, 1989). Tests for linkage disequilibrium were also performed at all pairs of loci using GENEPOP. Null allele frequencies were estimated with both CERVUS 2.0 (Marshall et al., 1998) and Microchecker (Van Oosterhout et al., 2004).

In addition, we tested whether hatching success (number of hatched eggs/number of incubated eggs) differed in subsequent clutches of a particular female, when sired by the same or different males. The difference between hatching rate in the first clutch and hatching rate in the second clutch was used as the dependent variable in ANOVA. The average values of hatchling mass $(\mathrm{g})$ and carapace length $(\mathrm{mm})$ per clutch were compared among the first and second clutches of the individual females through ANOVA. Normality of these variables and homogeneity of variances of the groups were previously confirmed after Kolmogorov-Smirnov test and Levene test, respectively.
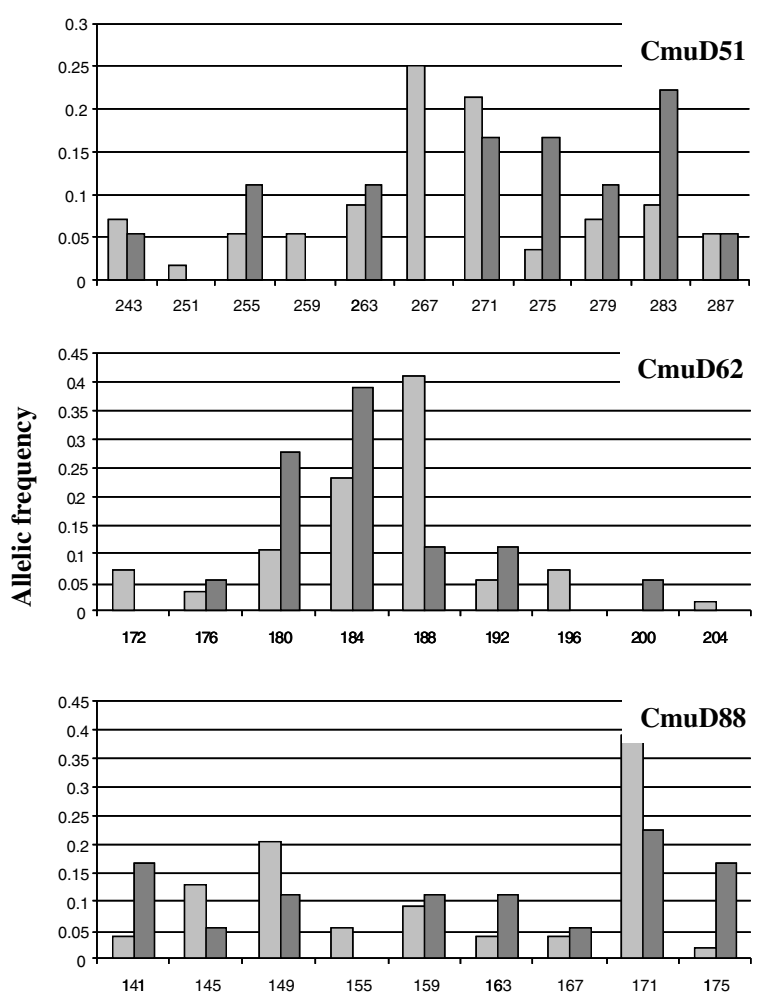

Alleles

\subsection{Paternity assessment}

Paternal alleles were deduced from the comparison of both maternal and offspring genotypes. We assumed that clutches with more than two paternal alleles were fathered by more than one male. A third paternal allele appearing in only one offspring at one locus was classified as the result of allelic mutation. To assess the suitability of our loci for parentage analysis, expected heterozygosity and average exclusion probabilities were calculated using the "allele frequency" module in the program CERVUS 2.0 (Marshall et al., 1998). The parentage analysis module available in CERVUS 2.0 was also used to calculate an assignment success of candidate parents to the offspring. For each offspring tested, parentage is assigned to the most-likely candidate parent with two pre-determined levels of confidence, referred to as relaxed (80\%) and strict (95\%). For example, any most likely candidate parent with a $\Delta$ score exceeding the critical $\Delta$ score for $95 \%$ confidence (estimated by simulation) is awarded parentage with $95 \%$ confidence.

\section{Results}

\subsection{Genetic background}

Relatively high genetic variability was observed among the individuals at all loci (mean number of alleles =9), with a maximum number at CmuD51, where 11 alleles were observed (Fig. 1). Expected heterozygosities varied between 0.760 and
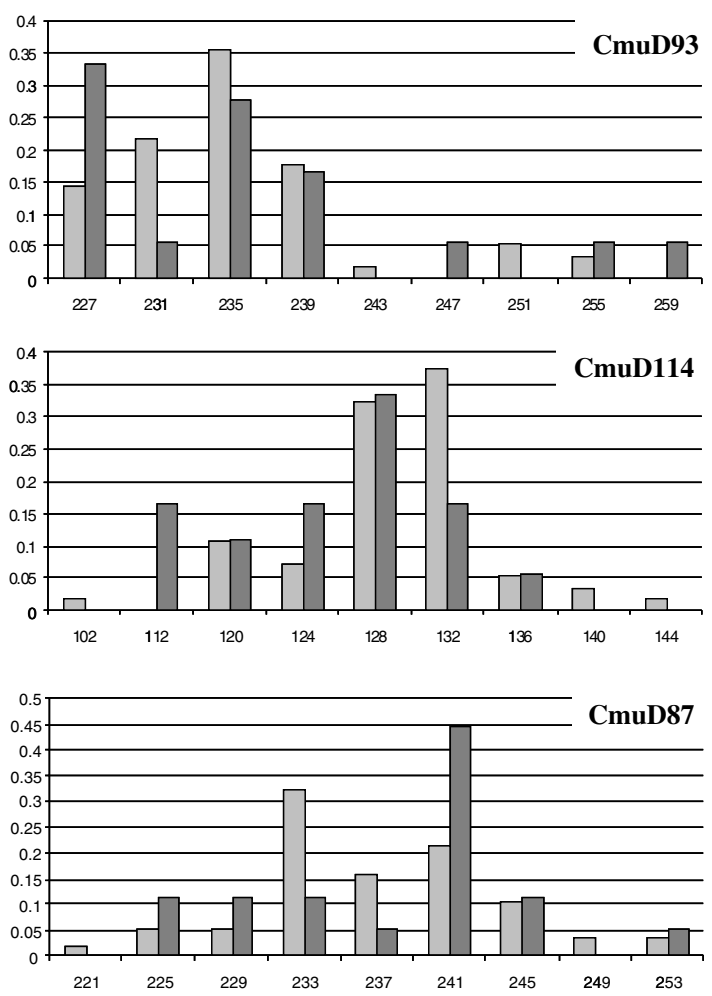

Fig. 1 - Allelic frequencies at six microsatellite loci determined in 37 E. orbicularis individuals from Pond 1 (light grey, $n=9$ ) and Pond 2 (dark grey, $n=28$ ) of the Doñana National Park. 
0.882 with a mean of 0.812 . Probability tests indicated that the total adult population was in Hardy-Weinberg equilibrium at all loci after sequential Bonferroni corrections $(p>0.01)$, with no evidence of heterozygote deficiency in any of the samples ( $p=0.73$ in Pond 1 and $p=0.93$ in Pond 2). Non-amplifying alleles could generally lead to mistaken conclusions and this is particularly important in parentage analyses (Pemberton et al., 1995). Null allele frequencies were null or very low in all loci, with highest values calculated with CERVUS in CmuD51 (2.8\%) and CmuD114 (2.9\%). Only one linkage disequilibrium, out of the 15 pair comparisons, was found between CmuD51 and CmuD87, but these loci are probably not physically linked, because linkage disequilibrium may occur by chance only or in genetically heterogeneous populations.

The combined paternity exclusion probability with one locus and one known parent varied between 0.539 and 0.743 , and was 0.997 when all loci were used. Parentage assignation success was of $100 \%$, at both $80 \%$ and $95 \%$ confidence levels and at all loci combined. We also found two offspring lacking maternal alleles at locus CmuD51 (AL5, AH3). These results may be due to a mutation of one of the maternal alleles, as these offspring were from the same nest. A similar mutation at the same locus was previously described in Testudo graeca (Roques et al., 2004).

\subsection{Paternity analysis and internesting strategy}

Multiple paternity was found in only two out of the 20 clutches or in two of the 11 females (Table 1), from which offspring displayed three paternal alleles at more than four loci (clutch B, 1564 and clutch AH, 1556; see Table 1). Therefore, a single male usually fathered all of the hatchlings in a clutch. Analyses of paternal alleles in successive clutches within a year indicated that both seasonal clutches were fertilized by the same male sperm (females 879, 1175 and 1599) (Table 1). Similarly, paternal alleles of clutches in 2002 and 2003 indicated that the second year clutches of four females were fertilized by the first year male (females 999, 1175, 1519 and 1564) (Table 1), and a different male sired the second year clutch of three females (females 879, 1564 and 1599). From the inferred paternal alleles, we found that one of the two clutches with multiple paternity (female 1564) involved stored sperm from the male of the previous year $(\mathrm{H} 2)$ plus sperm from another mating (H3). In this case, the allelic contribution of the stored sperm (H2) was much less (16.6\%) than the one from the latest mating. Also, clutches $\mathrm{H}$ (female 1599) and AH (female 1556) were partly (when multiple paternity occurred) or entirely fertilized by male $\mathrm{H} 2$.

\subsection{Hatching success, hatchling quality and paternal contribution}

Comparing hatching rate in successive clutches of a particular female, we observed significant differences between subsequent clutches sired by the same or another father $\left(F_{1,7}=10.3, p=0.01\right)$. Hatching rate was lower in the second clutch if sired by the same male than if sired by another male (Fig. 2). Hatchling mass $\left(F_{1,8}=16.5, p=0.004\right)$ and carapace length $\left(F_{1,8}=6.31, p=0.036\right)$ were significantly lower in second clutches when sired by the same male (Fig. 2).
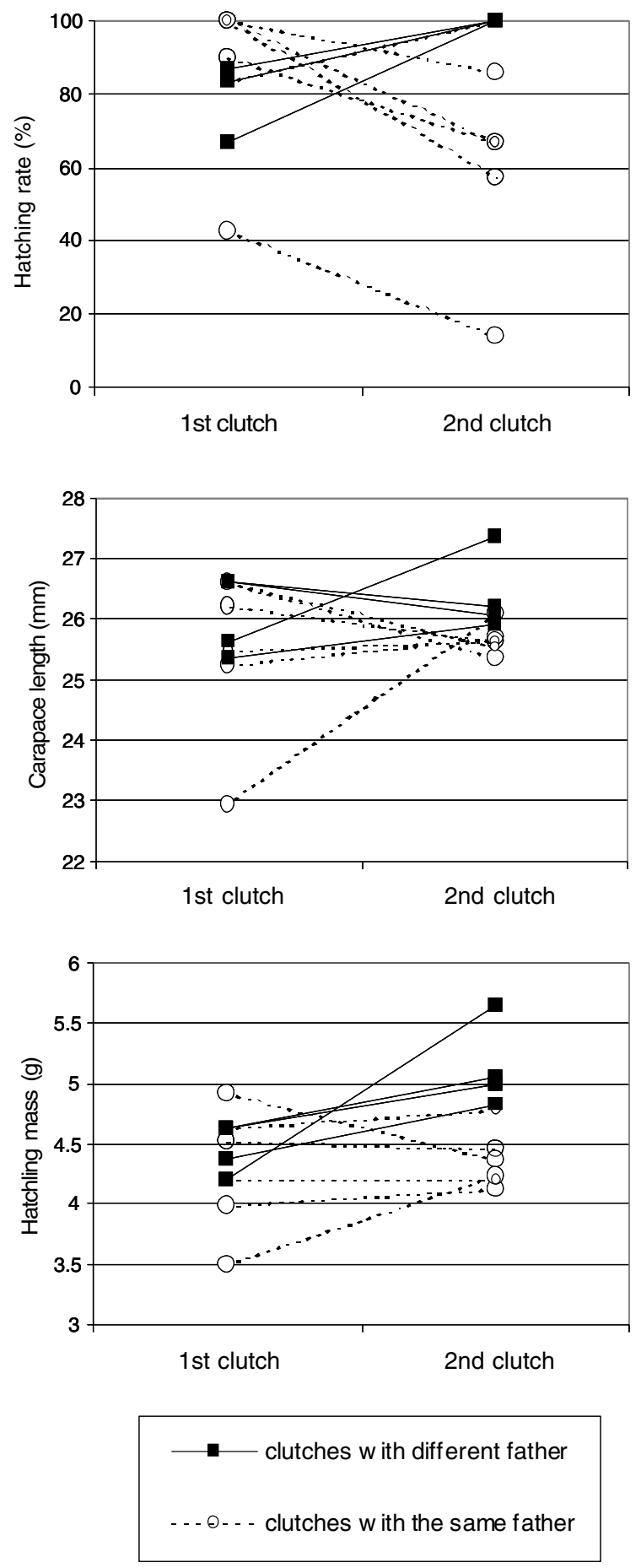

Fig. 2 - Hatching rate, average values of hatchling carapace length and hatchling mass in first and second clutches of a same female.

\section{Discussion}

\subsection{Sperm storage}

In this study, the same paternal alleles occurred in $100 \%$ and $58 \%$ of successive clutches of individual females, respectively within and between years, suggesting that E. orbicularis frequently stores sperm and uses it to fertilise subsequent 
clutches, both within and across breeding seasons. The alternative is that females show fidelity to specific males but this is unlikely because pair-bonds are not known to occur in turtles (Galbraith, 1993; Pearse and Avise, 2001). Moreover, in a study of mating behaviour of an Italian population, most males mounted more than one female and most females were mounted by different males (Rovero et al., 1999). Therefore, the use of stored sperm is a common strategy for the study population at least.

One benefit of sperm storage for females is to ensure fertilization of eggs in spite of asynchronous male and female reproductive cycles (Pearse and Avise, 2001). The main mating period of E. orbicularis is in spring and the number of clutches that females may lay per season is constrained by the length of the nesting season. Therefore, starting egg maturation early would enable a female to lay a higher number of clutches within a season. Sperm storage within the same breeding season is common in most turtle species and has generally been viewed as a mechanism that increases the number of clutches per year (Pearse et al., 2001; Roques et al., 2004). Alternatively, the percent of reproductive E. orbicularis females was very small in years of drought (Keller, 1997). If low mating success was low following a particularly bad year, then the use of stored sperm would ensure the fertilization of eggs.

Use of stored sperm, however, reduces fitness of E. orbicularis. Hatching rate, hatchling mass, and carapace length are reduced if successive clutches are sired by the same male. Stored sperm may be insufficient in number or may deteriorate over time. This result is congruent with the decline in fertility observed in the diamond terrapin, Malaclemys terrapin, following isolation of females from males for a year (Goin et al., 1978). Some recent studies, however, have observed that clutches fertilized in different years by stored sperm did not decrease in fertility (Palmer et al., 1998; Pearse et al., 2001). For example, in painted turtles, females used stored sperm for up to three years without significant differences in hatching success among subsequent clutches (Pearse et al., 2001). Therefore, as this strategy reduces reproductive success in E. orbicularis, it is not clear if any compensating benefits are obtained from storing sperm. Long sperm storage has been described in other turtle species up to three years in the painted turtles Chrysemys picta (Pearse et al., 2001) and up to six months in the soft-shelled turtle, Lissemys punctata punctata (Sarkar et al., 2003). One explanation for the occurrence of sperm storage is an unequal sex ratio and/or the non-availability of potential mates. For E. orbicularis however, opportunities for mating are not likely to be limited, given the comparable number of males and females at our study sites. On the other hand, many observations indicate that energetic costs may be high during mating. Frequent mounting with different males, long mating duration (up to three days) and consistent hierarchies and aggression among males suggests mating may be costly for both sexes (Rollinat, 1934; Rovero et al., 1999). The occurrence of sperm storage in our population may therefore indicate mating and/or fertilization process is costly, either because of low mating success (mounting does not necessarily translate in effective copulation), or because energetic costs during copulation may be high. Thus, when females do not succeed in acquiring new sperm by mating, they may simply use "old stored sperm", despite reduction in reproductive output.

\subsection{Multiple paternity}

Our genetic data indicated that multiple paternity is rare in $E$. orbicularis and that $90 \%$ of clutches have alleles of only one male. In general, the incidence of multiple paternity is highly variable and not related to clutch size (Pearse and Avise, 2001). Species such as marine turtles generally exhibit high frequencies of multiple paternity (Lepidochelys kempii, Kichler et al., 1999; Caretta caretta, Moore and Ball, 2002), although in Chelonia mydas populations with both low (9\%; Fitzsimmons, 1998) and high frequencies (Ireland et al., 2003; Lee and Hays, 2004) were found. Several direct benefits of multiple paternity have been proposed including the transfer of nutrients in the seminal fluids, the ability to fertilize large clutches, and to provide insurance of male fertility (Pearse and Avise, 2001), but such hypotheses have rarely been tested empirically. Among the few existing studies, most failed to demonstrate direct benefits of multiple paternity and did not find any relationship between multiple sired clutches and hatchling characteristics (Pearse et al., 2001, 2002; Lee and Hays, 2004). Therefore, apart from the indirect benefit of increasing genetic variation among offspring, reproductive advantages of multiple paternity in turtles still remain unclear and may be subtle. In our study, multiple paternity was detected twice (Table 1) and was not correlated with either higher clutch size or higher hatching success. The low incidence of multiple paternity found in our E. orbicularis population may be a residual consequence of the capacity of storing viable sperm for subsequent clutches. The low frequency of multiple paternity in our study underscores the point that mating systems that seem evident from observational data (e.g. multiple mounting observed in an Italian population by Rovero et al., 1999) may not correspond to what actually happens (e.g. mainly single paternity).

Sperm storage has also been viewed as an additional mechanism of mate choice if females can detect variation in sperm quality (Pearse and Avise, 2001). Although our sample size is relatively low, we cannot rule out the possibility of differences in sperm quality or quantity of different males. Both multiple sired clutches in this study involved the same male (H2), who also sired the majority (57\%) of the clutches genotyped in pond 2 (Table 1). As both cases of multiple paternity detected were associated with the same male, we think that H2 was a "best quality" male. He could have had high sperm viability or simply higher sperm production, which allowed females to store his sperm longer than the sperm of other males. Sperm competition via sperm storage may thus occur in this species, and females may use one or occasionally more than one male sperm, when a new mate of "high quality" is found to fertilize subsequent clutches.

\subsection{Implications for conservation}

E. orbicularis is a declining species throughout its European range, mainly as a consequence of habitat disturbance and climate change. It is included in IUCN Red List of Threatened Species in the category "lower risk/near threatened and 
declared "strictly protected" by Bern Convention. Gravid females as well as nest or neonate survival are the life history stages most critical to successful recruitment (and therefore to favour population stability) in freshwater turtle populations (Spinks et al., 2003). Our results suggest that factors associated with mating strategies may also play an important role in the maintenance of populations. Frequent sperm storage and single paternity in our E. orbicularis population have possible negative implications for its future conservation. First, because males are probably not a limiting factor, the frequent use of sperm storage may indicate mating process within ponds is costly and/or not often successfully performed, and that using stored sperm from previous mating is an alternative way of fertilizing eggs in successive clutches. Second, the association between sperm storage and sperm depletion or deterioration implies that the mating success of this population relies on a "risky" mating strategy, given that females have reduced reproductive output by using "old" male sperm. Therefore, an equal sex-ratio might not be sufficient to optimise the reproductive output. In very threatened populations, management strategies should aim to enhance effective copulations in order to increase the reproductive output of females. Methods could include increasing the sex ratio towards males, or even avoiding male competition with the isolation of mating pairs to favour effective copulation.

Mating systems have important implications for effective population size, level of inbreeding, and genetic diversity within and among populations. Multiple paternity is rare in E. orbicularis in south-western Spain, while it was more frequent in other turtles (Pearse and Avise, 2001; Ireland et al., 2003; Lee and Hays, 2004; Roques et al., 2004). This means that this population may also lack the advantages associated with multiple paternity, such as an increased effective population size and higher genetic variability (Sugg and Chesser, 1994).

In general, studies combining genetic, and observational, demographic and behavioural data may open new perspectives on the mating systems of freshwater turtles. Such studies could also provide important insights into the conservation of E. orbicularis and may be particularly relevant for the recovery of the species in geographic areas (e.g. Central Europe, Italy and southern France) where populations are small and declining.

\section{Acknowledgements}

We gratefully thank M. González Tirante assistance in the laboratory, C. Keller and R. Andrews for useful comments on the manuscript. This research has been supported by a Marie Curie Fellowship of the European Community Host Development programme under contract number HPMD-CT-2000-00009 and by Ministerio de Educación y Ciencia (project REN2002-03579/GLO).

R E F E R E N C E S

Crim, J.L., Spotila, L.D., Spotila, J.R., O’Connor, M., Reina, R., Williams, C.J., Paladino, F.V., 2002. The leatherback turtle,
Dermochelys coriacea, exhibits both polyandry and polygyny. Molecular Ecology 11, 2097-2106.

Devine, M.C., 1984. Potential for sperm competition in reptiles: behavioural and physiological consequences. In: Smith, R.L. (Ed.), Sperm Competition and the Evolution of Animal Mating Systems. Academic Press, London and New York, pp. 509-521.

Ewert, M.A., Legler, J.M., 1978. Hormonal induction of oviposition in turtles. Herpetologica 34, 314-318.

Fitzsimmons, N.N., 1998. Single paternity of clutches and sperm storage in the promiscuous green turtle (Chelonia mydas). Molecular Ecology 7, 575-584.

Fritz,U. 2001. Emys orbicularis (Linnaeus, 1758) - Europäische Sumpfschildkröte. In: Fritz, U., (Ed.), Handbuch der Reptilien und Amphibien Europas, Band 3/IIIA. Schildkröten (Testudines) I (Bataguridae, Testudinidae, Emydidae). Aula Verlag, Wiebelsheim, pp. 343-515.

Galbraith, D.A., 1993. Multiple paternity and sperm storage in turtles. Herpetological Journal 3, 117-123.

Gemmell, N.J., Akiyama, S., 1996. An efficient method for the extraction of DNA from vertebrate tissues. Trends in Genetics 12, 338-339.

Gist, D.H., Congdon, J.D., 1998. Oviductal sperm storage as a reproductive tactic of turtles. Journal of Experimental Zoology 282, 526-534.

Gist, D.H., Jones, J.M., 1989. Sperm storage within the oviduct of turtles. Journal of Morphology 199, 379-384.

Gist, D.H., Dawes, S.M., Turner, T.W., Sheldon, S., Congdon, J.D., 2001. Sperm storage in turtles: A male perspective. Journal of Experimental Zoology 292, 180-186.

Goin, C., Goin, O., Zug, G., 1978. Introduction to Herpetology, third ed. Freeman and Co., New York.

Hoekert, W., Neuféglise, H., Schouten, A., Menken, S., 2002. Multiple paternity and female-biased mutation at a microsatellite locus in the olive ridley sea turtle (Lepidochelys olivacea). Heredity 89, 107-113.

Ireland, J., Broderick, A., Glen, F., Godley, B.J., Hays, G.C., Lee, P.L.M., Skibinski, D.O.F., 2003. Multiple paternity assessed using microsatellite markers, in green turtles Chelonia mydas (Linnaeus, 1758) of Ascension Island, South Atlantic. Journal of Experimental Marine Biology and Ecology 29, 149-160.

Iverson, J.B., 1992. A revised checklist with distribution maps of the turtles of the world, Richmond, Privately printed.

Keller, C., 1997. Ecología de poblaciones de Mauremys leprosa y Emys orbicularis en el Parque Nacional de Doñana. Ph.D. thesis, Universidad de Sevilla.

Kichler, K., Holder, M.T., Davis, S.K., Márquez-M, R., Owens, D.W., 1999. Detection of multiple paternity in the Kemp's ridley sea turtle with limited sampling. Molecular Ecology 8, 819-830.

King, T., Julian, S.E., 2004. Conservation of microsatellite DNA flanking sequence across 13 Emydid genera assayed with novel bog turtle (Glyptemys muhlenbergii) loci. Conservation Genetics 5, 719-725.

Lee, P.L., Hays, G.C., 2004. Polyandry in a marine turtle: Females make the best of a bad job. Proceedings of the National Academy of Sciences of USA 101, 6530-6535.

Marshall, T.C., Slate, J., Kruuk, L., Pemberton, J.M., 1998. Statistical confidence for likelihood-based paternity inference in natural populations. Molecular Ecology 7, 639-655.

Moore, M.K., Ball, R.M., 2002. Multiple paternity in loggerhead turtle (Caretta caretta) nests on Melbourne Beach, Florida: a microsatellite analysis. Molecular Ecology 11, 281-288.

Olsson, M., Shine, R., 1997. Advantages of multiple matings to females: a test of the infertility hypothesis using lizards. Evolution 51, 1684-1688.

Olsson, M., Shine, R., Madsen, T., Gullberg, A., Tegelström, H., 1997. Sperm choice by females. Trends in Ecology and Evolution 12, 445-446. 
Palmer, K.S., Rostal, D.C., Grumbles, J.S., Mulvey, M., 1998. Long-term sperm storage in the desert tortoise (Gopherus agassizii). Copeia 1998, 702-705.

Pearse, D.E., Avise, J.C., 2001. Turtle mating systems: behaviour, sperm storage, and genetic paternity. Journal of Heredity 92, 206-211.

Pearse, D.E., Janzen, F.J., Avise, J.C., 2001. Genetic markers substantiate long-term storage and utilization of sperm by female painted turtles. Heredity 86, 378-384.

Pearse, D.E., Janzen, F.J., Avise, J.C., 2002. Multiple paternity, sperm storage, and reproductive success of female and male painted turtles (Chrysemys picta) in nature. Behavioural Ecology and Sociobiology 51, 164-171.

Pemberton, J., Slate, J., Bancroft, D., Barrett, A., 1995. Nonamplifying alleles at microsatellite loci: a caution for parentage and population studies. Molecular Ecology 4, 249-252.

Raymond, M., Rousset, F., 1995. GENEPOP (version 1.2): Population genetics software for exact test and ecumenism. Journal of Heredity 86, 248-249.

Rice, W.R., 1989. Analysing table of statistical tests. Evolution 43, 223-225.

Rollinat, R., 1934. La vie des reptiles de la France Centrale. Libraire Delagrave, Paris. reedited in1980 by Societé Herpétologique de France.

Rovero, F., Lebboroni, M., Chelazzi, G., 1999. Aggressive interactions and mating in wild populations of the European Pond turtle Emys orbicularis. Journal of Herpetology 33, 258-263.
Roques, S., Díaz-Paniagua, C., Andreu, A.C., 2004. Microsatellite markers revealed multiple paternity and sperm storage in the Mediterranean spur-thighed tortoise, Testudo graeca. Canadian Journal of Zoology 82, 153-159.

Sambrook, J., Fritsch, E.F., Maniatis, T., 1989. Molecular Cloning: a Laboratory Manual, second ed. Cold Spring Harbor Laboratory Press, New York.

Sarkar, S., Sarkar, N., Maiti, B., 2003. Oviductal sperm storage structure and their changes during the seasonal (dissociated) reproductive cycle in the soft-shelled turtle, Lissemys punctata punctata. Journal of Experimental Zoology, Part A - Comparative Experimental Biology 295, 83-91.

Spinks, P., Pauly, G., Crayon, J., Shaffer, H., 2003. Survival of the western pond turtle (Emys marmorata) in an urban California environment. Biological Conservation 113, 257-267.

Sugg, D.W., Chesser, R.K., 1994. Effective population sizes with multiple paternity. Genetics 137, 1147-1155.

Tenessen, J.A., Zamudio, K.R., 2003. Early male reproductive advantage, multiple paternity and sperm storage in an amphibian aggregate breeder. Molecular Ecology 12, 1567-1576.

Van Oosterhout, C., Hutchinson, W., Wills, D., Shipley, P., 2004. MICRO-CHECKER: software for identifying and correcting genotyping errors in microsatellite data. Molecular Ecology Notes 4, 535-538. 